\title{
Portfolio Issues Of Mobilization Insurance: What Went Wrong And Candidate New Offerings
}

Terrance Jalbert, (Email: jalbert@hawaii.edu), University of Hawaii, Hilo Mercedes Jalbert, (Email: mercedesjalbert@yahoo.com), Jayco TT

David Hammes, (Email: hammes@hawaii.edu), University of Hawaii, Hilo

\begin{abstract}
Financial hardships experienced by those in the military are well documented. Mobilization insurance has the potential to reduce the financial burdens of being called to active military duty. Reducing the financial burden of being called to active duty can provide numerous benefits to the military and Reservists including improved recruiting, lower attrition, and reduced stress on activated Reservists. In this paper, the Ready Reserve Mobilization Income Insurance Program and the reasons for its failure are discussed. The portfolio characteristics of the stakeholders involved in the Reserve system are analyzed in an options pricing framework and a discussion of how a new mobilization insurance product might be structured is examined. While the concept of offering such insurance is simple enough, no known academic research has analyzed the financial positions of Reserve system stakeholders.
\end{abstract}

\section{INTRODUCTION}

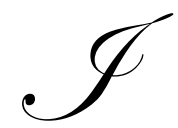
ins ave at times demonstrated an interest in developing an income protection plan for mobilized Reservists. The interest in such a program was understandably substantially reduced after the September 11,2001 attacks on the U.S. and the subsequent mobilization of large numbers of Reservists (DOD, 2004b). The lack of success of the initial product, and the ongoing interest in a new product, leaves open three research questions: What are the portfolio characteristics of the stakeholders involved in Reserve programs? Why did the first mobilization insurance program fail? And finally, can a new product be developed that would provide mobilization insurance without the pitfalls of previous products?

Military Reserves are intended as a supplementary military force to be called to active duty at the convenience of the country. That is, the military contracts individuals to be called away from their daily roles in society to serve in the military on those instances when their service is required. Individuals that become members of the military Reserves are obligated to spend one weekend per month and two weeks per year training. In addition to this commitment, the U.S. Government has the right to call up the Reserves for active duty at any time. An individual serving in the Reserves today faces a substantial probability that he/she will be activated once, and in many instances more than once. Those activated individuals are required to serve full-time for up to one year. As of December 31 , 2003, the average length of activation for recent operations was 319 days. This length of time is longer than previous missions (Kosovo, Bosnia, and Haiti) which averaged 200 days. However recent policies limit mobilization to one year, every six years (Department of Defense 2004b). The military clearly recognizes the financial hardships associated with an untimely Reserve mobilization. Nevertheless, the Reserves are intended for just such a purpose. 
Routinely offering waivers of mobilization orders based on financial hardship would certainly invite a flood of waiver applicants, causing substantial personnel problems in the military. While recognizing the hardships imposed as a result of the mobilization and the simultaneous need for the mobilization, the military can do certain things to minimize the financial impact of the mobilization. In a world of complex financial securities a number of issues can be resolved by way of carefully structured financial products. This paper begins by providing data on the U.S. Military Reserves and demographic information about the Reservists followed by a discussion of the potential for financial loss of a Reservist called to active duty. Next, an options analysis of the economic position of the Reservist, their employers and the military is developed. The analysis continues by discussing a previous attempt to offer an insurance program to Reservists called the Ready Reserve Mobilization Income Insurance Program (RRMIIP) and follows with a discussion of why this product failed. Next, candidate characteristics of a new Mobilization Insurance Product are discussed. Finally, concluding comments and recommendations for moving the insurance product forward are provided.

\section{DATA ON MILITARY RESERVES}

Excluding the Coast Guard Reserves, the U.S. Military Reserves consisted of 1,209,200 personnel as of September 30, 2002. The Coast Guard has an additional 13,137 Reservists. This total consists of 874,326 Selected Reserves, 312,062 Individual Ready Reserves and Inactive National Guard and 22,812 Standby Reserves. The total number of Reserves has declined from 1,882,659 personnel in 1992 to its current level (DOD, 2002, p. 153). Military Reserves are not limited to the U.S. A large number of other countries also utilize some reserve type of system. Canada has approximately 15,000 Reservists (Reserves 2000, 2005). Egypt has 300,000 Reservists, Jordan 30,000 (Golden, 2005). The United Kingdom has about 268,000 Reservists (Ministry of Defense 2001/2002). Thus this research will benefit not only the U.S. Military but also the military of our allies and friends.

Military Reservists come from a variety of backgrounds and work in a variety of careers in their civilian lives. These demographic characteristics of Reservists are known and tracked by the military. Selected Reserve Officer Accession data from 2001 indicates that 53 percent of Reserve component officers have at least a bachelor's degree. In addition, 31.59 percent have additional college education (DOD, 2003, Appendix C). Military Reservists have a lower percentage of marriage than their civilian counterparts. Overall, 48.1 percent of Reservists are married versus 54.3 percent for similar aged civilians. When analyzed by gender, 50.1 percent of male Reservists are married while 55.6 percent of similar male civilians are married. The difference is more pronounced among women. While 34.7 percent of women Reservists are married, 52.8 percent of their civilian counterparts are married (DOD, 2003, Chapter 5). Eleven percent of Reservists work in a family business or are self-employed. An additional 17 percent work in companies with fewer than 100 employees. Forty-two percent work in companies with more than 100 employees. Thirty-two percent work for the Federal, a State, or a Local Government (DOD Reserve Component Survey, 2000). These substantial differences in demographic and civilian employment characteristics of Reservists make designing equitable and motivating compensation schemes difficult at best. Given these difficulties and the motivations of various interested parties, a number of laws protecting Reservists have been passed. These protections are discussed in the following section.

\section{PROTECTIONS OFFERED TO RESERVISTS}

Many laws have been passed to provide various types of financial protections for Reservists. In this section, we introduce some of the primary protections that Reservists have. This discussion is not intended to be exhaustive, but rather as an introduction to elements of the law directly related to the research at hand. Congress has long recognized that the financial well being and job security of Reservists are integral elements of the success of reserve programs. The Uniformed Services Employment and Reemployment Rights Act (USERRA), (Title 38, U.S. Code Chapter 43, Section 4301-4333, Public Law 103-353) which was passed in October of 1994 and modified in 1996, 1998 and 2000, defines the rights and responsibilities of the Reservists and their employers. One of the critical elements of USERRA is the reemployment rights it grants to the Reservist. Specifically, Reservists have the right to be reemployed if they provide advance notice to the employer of the military service, they have five years or less of cumulative military service while with the employer, they return to work in a timely manner after the conclusion of the military service, and they have not been discharged from the military under other than honorable conditions. The 
Soldiers' and Sailors' Civil Relief Act (SSCRA), first passed in 1918 and updated in 1991 and again in 2003 by the Servicemembers' Civil Relief Act(SCRA), can ease the financial burden of a war. Among other things, it halts foreclosures and evictions in many instances. It provides that life insurance protection can not lapse while the individual is on active duty or for up to two years afterwards. It also grants the member a 6 percent interest rate on credit cards, auto loans, mortgages, equity lines and other installment loans (Phipps, 2005).

In addition to specific laws that protect Reservists, certain additional benefits are provided to the Reservists and their employers. The Military Reservist Economic Injury Disaster Loan (MREIDL) provides loans designed to aid firms when key personnel are called to serve in the military. The loans are available for amounts of up to $\$ 1.5$ million where a small business can demonstrate that it has been adversely affected financially by the loss of a key employee. The loans are available for up to 30 years and carry a maximum interest rate of 3.5 percent. However, the request for the loan must be made between the date that the individual is called to active duty and up until 90 days after the individual is discharged. The loans are administered by the Small Business Administration (SBA). Collateral and personal guarantees are required to secure the loans. The loan program was initiated in response to the Kosovo conflict (McCune, 2005). In addition to formal laws and benefits, agencies have been developed to work with Reservists' employers. The National Committee for Employer Support of the Guard and Reserve (ESGR) operates a program directed to gain and maintain active support from the public and private employers of individuals in the Guard and Reserves (Department of Defense, 2004). Among other things, the ESGR measures employer's level of commitment using a 1 through 5 scale at the time that employers sign a Statement of Support (ESGR, 2004). These rankings are published on the ESGR website (ESGR, 2005).

\section{THE POTENTIAL FOR FINANCIAL LOSS}

Despite the protections afforded in the laws cited above, there remains substantial potential for financial loss for Reservists. Even though individuals may be well aware of the risks they face when they enter the military Reserves, financial difficulty associated with a mobilization is frequently experienced. The potential for financial loss primarily, but not exclusively, occurs because the pay earned by activated Reservists is less then the pay earned in the civilian sector. These difficulties are well documented with stories regularly appearing in the media. Bankrate.com recently reported an article about a medical doctor who was called up for active duty. The result was a severely damaged medial practice and personal bankruptcy. The soldier says "I guess most of us went into it somewhat blind, thinking Uncle Sam would take care of us, and obviously Uncle Sam doesn't." (Ray and Abramowitz, 2005). Such an outcome is bad for the soldiers' morale, retention, and recruitment. While the U.S. Military compensates activated individuals for their time, for some Reservists this compensation does not offset the loss in pay associated with their regular work. The evidence on the extent to which this is the case is mixed. A recent Department of Defense (DOD) news article cites a DOD survey indicating that about two-thirds of the 268,000 Reserve soldiers activated during the first Gulf War suffered an economic loss. Those individuals who were self employed were found to experience the largest losses (American Forces Press Service, 1997).

The 2002 Survey of Spouses of Activated National Guard and Reserve Component Members, commissioned by the Office of the Assistant Secretary of Defense for Reserve Affairs (OASD/RA) and conducted by Caliber Associates paints a somewhat different picture. This survey produced 3,874 usable observations. The survey indicates that in fact, many individuals experience an income increase associated with a mobilization. Table 1 reports the results of the survey regarding income. Overall, 58 percent of spouses reported an increase in income associated with the activation, 11.2 percent reported no change and 30.8 percent reported a decrease in income. The table indicates that the largest decrease in earnings was reported by individuals in the Navel Reserves. By rank, the largest losses were incurred by senior officers.

The magnitude of the increase or decrease in income is reported in Table 2. Nearly 23 percent of all individuals reported a decrease in income that exceeded $\$ 500$ per month while 38.7 percent of all individuals reported an increase in income that exceeded $\$ 500$ per month (Caliber Associates, 2003). The GAO reports that the average loss in income for reservists was just under $\$ 1,700$ per month for deployments prior to 2001 . The loss varied by occupation with self employed reservists reporting a $\$ 6,500$ per month loss in income. Physicians and registered nurses in private practice reported a loss of more than $\$ 25,000$ per month (Stewart, GAO, 2003). Unfortunately, the 
survey does not clearly identify what constitutes income. In addition, the survey examines only the families of those individuals that joined the Reserves. Future research should examine the economic motivations of individuals who were interested in joining the Reserves, but elected not to do so because of the potential for economic loss. Such research would help identify the extent to which financial considerations limit recruitment.

Financial hardships associated with a mobilization are particularly problematic in situations where the pay earned in the civilian sector is substantially more than the pay earned while on active duty, or when the individual provides some unique contribution in the civilian sector that is not easily replicated by a substitute. Likely professions where this might be expected include medical doctors, dentists, attorneys, and business owners. Moreover, individuals like professors, who may not face an immediate pay cut, may not be able to maintain their publishing activity while on active duty, thereby decreasing their probable future income. Others, like professional athletes, may no longer find themselves able to perform at the level required to maintain their professional career.

Table 1: Earnings Changes Associated With Activation

\begin{tabular}{|l|c|c|c|}
\hline & $\begin{array}{c}\text { Increase In } \\
\text { Earnings }\end{array}$ & $\begin{array}{c}\text { No Change in } \\
\text { Earnings }\end{array}$ & $\begin{array}{c}\text { Decrease in } \\
\text { Earnings }\end{array}$ \\
\hline Panel A: By Reserve Component & & & $25.4 \%$ \\
\hline Army National Guard & $65.3 \%$ & 9.3 & 32.4 \\
\hline Air National Guard & 54.6 & 13 & 33.7 \\
\hline Army Reserve & 55.5 & 10.8 & 34.4 \\
\hline Air Force Reserve & 52.2 & 13.4 & 40.4 \\
\hline Naval Reserve & 46.7 & 7.7 & 38.5 \\
\hline Marine Corps Reserve & 53.8 & & \\
\hline Panel B: By Rank & & 7.4 & 32.5 \\
\hline Junior Enlisted & 60.1 & 11.8 & 33.7 \\
\hline Senior Enlisted & 54.5 & 12.1 & 22.4 \\
\hline Warrant Officers & 65.5 & 24.6 & 9.9 \\
\hline Junior Officers & 65.4 & 11.6 & 35.4 \\
\hline Senior Officers & 53.0 & & \\
\hline Panel C: Overall & & 11.2 & 30.8 \\
\hline Overall & 58.0 & & \\
\hline
\end{tabular}

Table 2: Levels Of Income Changes Associated With Activation

\begin{tabular}{|l|c|}
\hline Monthly Income Change & $3.0 \%$ \\
\hline$>-\$ 3,500$ & $3.8 \%$ \\
\hline$-\$ 2,001$ to $-\$ 3,500$ & $7.4 \%$ \\
\hline$-\$ 1,001$ to $\$ 2,000$ & $8.4 \%$ \\
\hline$-\$ 501$ to $-\$ 1,000$ & $6.0 \%$ \\
\hline$-\$ 251$ to $-\$ 500$ & $2.2 \%$ \\
\hline$-\$ 1$ to $\$ 250$ & $11.2 \%$ \\
\hline No Change & $7.6 \%$ \\
\hline$\$ 1$ to $\$ 250$ & $11.7 \%$ \\
\hline$\$ 251$ to $\$ 500$ & $16.4 \%$ \\
\hline$\$ 501$ to $\$ 1,000$ & $14.2 \%$ \\
\hline$\$ 1,001$ to $\$ 2,000$ & $5.9 \%$ \\
\hline$\$ 2,001$ to $\$ 3,500$ & $2.2 \%$ \\
\hline$>\$ 3,500$ & $100 \%$ \\
\hline Total & \\
\hline
\end{tabular}

While laws extend employment protection to Reservists, there remain problematic areas. USERRA applies only to employed individuals. A small business owner is not provided any similar protection. A small business owner that owns a janitorial service and closes His/her business while he is serving actively is provided no protection that his customers will return to his business upon his return. The patients of a medical doctor may locate a new 
physician when their Reservist doctor is called away to active duty. Some of these patients would clearly not return to the Reservist doctor upon the doctors return to his private practice. A business owner might be forced to close his/her business, losing clients that may have long term commitments to his/her firm. He may even be required to honor his contracts to his clients by purchasing a replacement service on the client's behalf. Moreover, while the professor who is called to active duty may be protected in his current employment, no such protection is provided to future employment. While on active duty it is not likely that the individual would be able to maintain his/her non-teaching academic responsibilities.

Offsetting some of the losses of the Reservist are contributions by the individuals employer. While some firms supplement the pay of their employees that are called to active duty, these supplements are often of limited duration. An article by Joel Dresang, in The Milwaukee Sentinel reports on a survey of Wisconsin employers conducted by MRA-The Management Association, Inc. The survey indicates that 71 percent of employers paid no supplements to management and professional employees on active duty, 42 percent discontinue employer-paid health insurance and 47 percent suspend accrual of vacation benefits (Dresang, 2003). The Reserve Officer Association conducted a survey of Fortune 500 companies. Of 154 firms that responded to the survey, 105 offer a pay differential to activated Reserve employees. Only 17 offered no financial benefits to activated Reservists. Employers are under increased pressure from the public to provide these benefits as is evidenced from the publicly reported employer rating system of the ESGR described above. Socially persuading firms to provide benefits to Reservists, effectively transfers an element of the cost of Reservists from the Military to the private sector.

In addition to the losses experienced by the individual being mobilized and their families, at least two additional parties can experience losses due to a mobilization. The first of these parties is the individual's employer. Among other things, the employer may have invested considerable money in training the individual. Providing the training to another temporary individual can be costly. Another party that can experience a negative outcome associated with the mobilization is local communities. Indeed, all of the approximately 200 American Samoa Reservists were activated simultaneously. Depending upon the makeup of the Reserves, this type of call up can have a significant negative impact on the local community. Specifically, in this case, the community relies heavily on the Reserves to provide emergency services.

\section{PORTFOLIO CONSIDERATIONS}

Financial hardships associated with being called up for active duty clearly have an impact on the willingness of individuals to join the Reserves initially, and to remain in the Reserves for extended periods of time. Moreover, those individuals who are members of the Reserves must manage their portfolios in such a way as to minimize the damage to the overall portfolio in the event that there is a mobilization. That is, they may need to make sub-optimal investment choices to offset the portfolio effects associated with being called up to active duty. They may also need to make suboptimal employment and family decisions because of the chance of activation. Understanding these portfolio effects are critical to understanding why individuals enlist in the Reserves, the reasons they chose to extend or not extend their tours of duty as well as the morale of the Reservist. In this section, a basic framework is developed for analyzing the financial positions the stakeholders involved in Reservist programs.

In an options pricing framework, a Reservist has sold a call option to the U.S. Military. The U.S. Military has purchased a call option on the time of the Reservist. The premium on the option is the present value of the expected benefits that individuals in the military receive, including the G.I. Bill, retirement benefits, financial compensation and other benefits afforded the Reservist. The portfolio of the Reservist is expressed in equation (1).

$$
V_{R P}=\sum_{i=1}^{n} \frac{\text { PremCall }^{n}}{(1+i)^{n}}+\sum_{i=1}^{n} \frac{\text { Vow }_{n}-\left(V_{o w}-V w a_{n}\right)}{(1+i)^{n}}(1-P)+\sum_{i=1}^{n} \frac{V w a_{n}-\left(V w a_{n}-V w m_{n}\right)}{(1+i)^{n}} P+\sum_{i=1}^{n} \frac{\text { Voi }_{n}-\left(\text { Voi }_{n}-V i a_{n}\right)}{(1+i)^{n}}
$$


Where:

$\begin{array}{ll}\mathrm{V}_{\mathrm{RP}} & =\text { value of the Reservist's portfolio } \\ \mathrm{i} & =\text { the individuals required rate of return } \\ \mathrm{Vow}_{\mathrm{n}} & =\text { the value of the individual's optimal work } \\ \mathrm{Vwa}_{\mathrm{n}} & =\text { the value of the work accepted in light of his/her military obligations } \\ \mathrm{Vwm}_{\mathrm{n}} & =\text { the value of the work in the military } \\ \mathrm{Voi}_{n} & =\text { the value of the individual's optimal investments } \\ \mathrm{Via}_{\mathrm{n}} & =\text { the value of the individual's investments accepted in light of his/her military obligations } \\ \text { PremCall } & =\text { The economic value that the individual receives for enrolling and being a part of the Reserves. } \\ \mathrm{P} & =\text { the probability of being activated for duty }\end{array}$

The first term in the equation is the present value of the benefits that an individual receives from being in the Reserves. It includes compensation, educational benefits, and so forth. These benefits will not be valued equally by all individuals. For example, the college benefits provided in the premium might be the only way some individuals can achieve a college education, while other individuals come from families having sufficient resources to attend college with our without military benefits. The second term in the equation is the value of the work income of the individual. The value of the individuals work is reduced to the extent that the individual accepts a suboptimal job in his civilian life because of his obligations to the military. While we do not compare the distribution of civilian jobs selected by Reservists as compared to the general population, or the extent to which the selection is suboptimal, the existence of any suboptimal job selection could explain differences between Reservists and general population employment. To the extent that insurance can mitigate certain employment risks, the distribution of civilian work by Reservists can be expected to change. The third term in the equation is the compensation that the individual receives if he is activated. To the extent that the income received in activation is below his civilian income, the value of the portfolio will be reduced. To the extent that the income received from the activation is above the civilian income, the value of the portfolio is enhanced. While activation that enhances the portfolio suggests the possibility that the Reservist simply enlist full-time, this may not be an optimal solution for the Reservist. Specifically, instances could occur where the compensation of the activated Reservist is higher than that of a full-time enlisted soldier. Moreover, full-time activation might be for a time frame that is not optimal for the soldier. Finally, the last term of the equation relates to investment income. To the extent that an individual must make suboptimal investments because of his military obligations the value of the portfolio is reduced.

An individual will enter into the Reserves whenever the benefits received by the Reservist exceed the cost of participating in the Reserves. That is, whenever the premium that the individual receives on the call option exceeds the cost he/she incurs as demonstrated in equation 2.

$\sum_{i=1}^{n} \frac{\text { PremCall }^{n}}{(1+i)^{n}}>\sum_{i=1}^{n} \frac{\left(\text { Vow }_{n}-V w a_{n}\right)}{(1+i)^{n}}(1-P)+\sum_{i=1}^{n} \frac{\left(V w o_{n}-V w m_{n}\right)}{(1+i)^{n}} P+\sum_{i=1}^{n} \frac{\left(\text { Voi }_{n}-\text { Via }_{n}\right)}{(1+i)^{n}}$

Any time the premium does not exceed the costs identified in equation 2, the individual will forego enlisting in the Reserves, or extending his/her tour of duty. When this is the case, the military will experience difficulty finding individuals that are willing to serve. Elements that serve to increase the call premium, or decrease the costs associated with being in the military will increase the chance that the individual will join, and remain in the Reserves. Equation 2 has another important implication. That is, those individuals who are most likely to join the reserves are those whose private sector earnings are the lowest relative to their military pay. Presumably, those individuals who are paid the most in the private sector earn these amounts because of their exceptional skills. If this is the case, the military will have difficulty recruiting those candidates with exceptional skills. To the extent that the military needs more individuals with exceptional skills than are available currently, the compensation system is lacking. Mobilization insurance or some other product that would reduce the pay differential on a case by case basis could rectify this problem. It is important to note that Equations 1 and 2 model only the decision to initially sign up for the Reserves, the decision to extend tours of duty by existing Reserve members require additional modeling. This 
additional modeling must take into account the effect on retirement plans and the individuals new assessment of being activated. Such modeling is beyond the scope of this paper and will be addressed in future research.

The position of the military can also be modeled in an option pricing framework. Given a certain manpower requirement in the event of a war, the military has two choices to achieve those manpower levels. With the assumption of an all volunteer military, one alternative is to employ full time soldiers to meet the entire manpower needs of the military. Of course, in times of peace, the military would be substantially overstaffed. Alternatively, a system of Reserves keeps the military at appropriate levels in times of peace with the ability to increase the number of trained military individuals in the field very rapidly. As noted above, by enlisting someone in the Reserves, the military has purchased a call option on the individual. It can exercise its option to activate the individual for a certain period of time. The military pays a premium on the call option that the Reservist receives. The benefit to the military is that its costs are reduced in peacetime. Defining $\mathrm{Vftw}_{\mathrm{n}}$ as the value of the military earnings of a full-time soldier, the portfolio of the military can be viewed as follows:

$V_{M P}=\sum_{i=1}^{n} \frac{V f t w_{n}}{(1+i)^{n}}(1-P)-\sum_{i=1}^{n} \frac{\text { PremCall }}{(1+i)^{n}}$

Equation 3 indicates that the money that the military will save by utilizing Reserves rather than a full-time soldier are equal to the earnings of the full time soldier during the peacetime period weighted by the probability that the soldier will be called to active duty. The cost to the military is the call option premium. The military is better off using Reservists as long as the present value of the expected premiums are less than the cost of maintaining a full-time soldier during peace time minus the benefits that the soldier provides to the military during peacetime.

The position of the Reservists' employer can also be examined. To the extent that an employer can costlessly replace an activated Reservist, the employer will not experience a loss. However, any time that the company must incur dual expenses, or a loss in productivity due to an activation, the firm is affected. The costs that an employer might experience include the cost of hiring, training and terminating a replacement employee, reduced productivity, and the cost of ongoing employment benefits, to the extent that they are offered to the activated Reservists. Presumably the mobilized Reservist was the optimal person to be working at the civilian job that he holds. If the mobilized Reservist is the optimal person, any replacement must be suboptimal. That is, they will have a lower productivity for the wages being paid. Moreover, knowing that the position is temporary in nature, the temporary employee might require a higher salary, or be expected to have a lower morale. The cost of activation to an employer can be written as follows:

$$
C A=\sum_{i=1}^{n} \frac{(V p)(P M-P R)_{n}}{(1+i)^{n}}+\sum_{i=1}^{n} \frac{B M n}{(1+i)^{n}}+\sum_{i=1}^{n} \frac{T C n}{(1+i)^{n}}
$$

Where:

$\mathrm{Vp} \quad=$ is the value of a unit of productivity

$\mathrm{PM} \quad=$ is the productivity of the mobilized Reservist

$\mathrm{PR} \quad=$ is the productivity of the replacement worker

$\mathrm{BM} \quad=$ the ongoing benefits offered to the mobilized Reservist

$\mathrm{TCn}=$ the cost of training the replacement worker

The framework introduced here is intended to be introductory, and suitable for many audiences. It is intended to simply introduce the issues involved. While this model addresses the basic issues, many additional, relevant elements can be incorporated into this framework. Those elements will be the topics of future research efforts. 


\section{THE READY RESERVE MOBILIZATION INCOME INSURANCE PROGRAM (RRMIIP)}

One solution to the financial problems faced by Reservists is for the military to simply increase the pay of the soldier while he is on active duty. To some degree this has been undertaken in recent years. Several other recent DOD policies can serve to offset the differences between military and civilian pay. These policies include changes to housing allowances and allowing Reservists to receive per diem in more instances. (Department of Defense, 2004b). However, doing so on a massive scale to offset the civilian pay of each individual would be expensive, would not reflect the fact that different individuals have differing financial obligations, and would not reflect differing investment portfolios of the individuals. Moreover, it could cause morale problems in the military if activated Reservists were paid more than full-time soldiers. Insurance provides a solution in the sense that each individual can select a level of insurance that is appropriate for him or her. Different individuals have different earning power in the private sector, will be affected to greater and lesser degrees by a mobilization, and have different personal responsibilities. Because of these differences, insurance provides additional flexibility that allows the Reservist to select the level of benefits that are appropriate for his/her own unique situation.

In 1996, Congress enacted the Ready Reserve Mobilization Income Insurance Program (RRMIIP) as part of the fiscal 1996 Defense Authorization Act. The United States Code Title 10, Subtitle E, Part II Chapter 1214, Sections 12521-12533 contains the relevant law. RRMIIP allowed individuals to purchase from $\$ 500$ to $\$ 5,000$ of payoff per month in $\$ 500$ increments. The benefits were payable for up to one year. The premium was $\$ 12.20$ per month per thousand dollars of insurance purchased. An individual purchasing $\$ 5,000$ of insurance would pay $\$ 61$ per month or $\$ 732$ per year. The maximum payoff, in the event of a mobilization lasting for one year or more, was $\$ 60,000$. Benefits were not payable until the individual had been on active service for 30 days. The insurance was value insurance rather than indemnity insurance. That is, the individual did not need to demonstrate that he had a loss. Rather, the insured was paid the benefit regardless of the extent of actual losses (Lee, 1997). Reservists who entered the military on or after Oct. 1, 1996 were automatically enrolled at the $\$ 1,000$ level. They were given 60 days to affirm, modify the level of insurance, or decline the insurance. If no action was taken, the Reservist was dropped from enrollment (Lee, 1997). The Secretary of Defense set the premium and was authorized to change the premium. However, once a Reservist locked in the current rate, the rate would remain fixed throughout his time with the military. In order to collect benefits the Reservists' orders had to specify that the members duty was in support of war, national emergency, or to augment active forces for a contingency operation. The insurance was continuous unless the member failed to pay the monthly premiums for two consecutive months. The Secretary of Defense was authorized to purchase an insurance policy that would provide the benefits. Such a purchase would have effectively outsourced the insurance product. In addition, a fund was established to accumulate and invest the premiums, any appropriations to the fund, as well as to pay benefits due to Reservists under the fund. The monies contained in the fund were to be invested by the Secretary of the Treasury in public debt securities.

\section{WHAT WENT WRONG WITH RRMIIP?}

The failure of the Ready Reserve Mobilization Income Insurance Program (RRMIIP) can be attributed to several factors. The first reason for the failure was a low participation rate. In 1997, only about 24,000 or 3 percent of 900,000 eligible soldiers participated in the program. The lack of participation in the program has been attributed to a number of factors. Lee (1997) cites four reasons for the failure of the program. The most notable factor was that those in the Reserves prior to October 1, 1996 had until December 1, 1996 to enroll in the program (Armed Forces Press Service, 1997). Those Reservists that did not take action to enroll were automatically denied participation in the program. The relatively short action window may have had a substantial impact on the number of Reserves that enrolled. Utilizing Reservists' responses to a 1991 and 1992 Department of Defense survey, the Rand Corporation suggested that 40 percent of eligible Reservists would purchase the insurance. A subsequent study of low participation rates indicated that 43 percent of Reservists were either not aware of the program or lacked sufficient information or time to make a decision to enroll. In addition, individuals may have been confused about their eligibility for the program as the sign-up period coincided with the mobilization of Reservists for duty in Bosnia. Moreover the product was not implemented with automatic payroll deduction. Finally, Lee (1997) suggests that large segments of the Selected Reserves may have concluded that the likelihood of their activation was sufficiently remote to make purchasing the insurance unnecessary. 
Another reason for the failure was that the product suffered from an adverse selection problem. The RRMIIP was not endowed with a reserve fund in the event that a military action including massive mobilizations were enacted in the early stages of the program. The lack of a reserve fund, along with a large mobilization associated with operation Joint Endeavor in Bosnia caused the program to become insolvent early on. Had a reserve fund been established, the product may have survived the initial benefit draw. Without a reserve fund, the chain of events led to the demise of the program. In addition, the product failed in part because individuals who knew they would likely be called to active duty in Operation Joint Endeavor were allowed to purchase insurance. Not surprisingly, they purchased large amounts of the insurance. On the other hand, few other eligible individuals purchased the insurance (Armed Forces Press Service, 1997). In essence, the product was saddled with an adverse selection problem from the start.

A variety of other issues may have limited the desirability of the program. It is possible Reservists have utility functions that are not risk averse. Individuals that join the reserves may have a risk seeking utility function. If Reservists have such a utility function, they may not be willing to purchase the insurance at any price. A lack of program options may have also adversely affected enrollment. The program was designed as a "one size fits all" program. The only election that the individual was allowed to make was on the amount of the insurance to be purchased. Additional program options may have increased the popularity of the program. The product may also have been perceived to be priced actuarially unfairly. Soldiers may have viewed the insurance to be too expensive given their perceived likelihood of being called to active duty. Moreover, given that the insurance did not pay off unless the soldier was activated for more than 30 days may have been a problem. Soldiers may have viewed the more likely scenario to be a mobilization for less than 30 days. A call up of more than 30 days would likely have been a result of a major military conflict, possibly viewed as being an unlikely scenario. In addition, the soldier might not have been able to accurately estimate the financial losses that he/she would experience in the event of a mobilization. Some evidence of this can be seen in the differential estimates of loss noted in previous research. While some financial hardships can be predicted with some accuracy, other hardships may not be easily predictable.

\section{Is there Hope for Mobilization Insurance?}

While a substantial amount of attention has been focused on solving problems faced by Reservists, the ongoing financial difficulties experienced by many activated individuals, clearly suggests a need for additional research into how these problems might be mitigated. An optimal solution would be to the benefit of both the U.S. Military and the personnel of the military. One candidate would be to re-instigate RRMIIP. RRMIIP continues to offer the promise of offsetting the financial losses experienced by activated Reservists either in part or in whole. Like the previous product, the product proposed here would allow the Reservist to collect supplemental pay in the event that he/she is activated for duty. However, we discuss several variants of the insurance that might make the product more widely accepted. We continue by discussing variants of the insurance.

Monthly compensation insurance, as was implemented in the initial RRMIIP, provides the Reservist, or some benefactor paying a premium to the insuring agency throughout his/her years in the Reserve a benefit in the event of activation. In the case of the original RRMIIP, the premium was $\$ 12.20$ for each $\$ 1,000$ of insurance purchased. While this remains a desirable option, it is by no means the only type of insurance that could be provided.

Single payoff insurance could involve a fixed payment rather than a monthly payment. An individual might pay $\$ 100$ per month. In the event that he is called to active duty, the insurance would pay a one time sum of $\$ 10,000$. This type of insurance would be desirable for individuals who will incur certain expenses regardless of how long the activation is. A dairy farmer might sell his herd of cattle prior to reporting for duty, possibly taking a loss. The expenses he will incur to replace the herd will be the same if the call up is for 270 days or 30 days. A fixed amount insurance payoff would be desirable in this situation.

Disability insurance could provide insurance in the event that the soldier becomes disabled while on active duty. In this case, an individual who becomes disabled during the course of active duty would be compensated for the remainder of his life, or some other time frame. Of course the military currently offers certain benefits to its disabled veterans; however, these benefits may not be sufficient to accommodate the lifestyle to which the Reservist has 
become accustomed. The difficulty with this type of insurance is determining what constitutes a disability. For example, many soldiers experience Post Traumatic Stress Disorder from military service. Decisions would need to be made regarding the extent to which this illness is a covered disability. This particular insurance product might be offered to both Reserve and Regular Military soldiers.

Life insurance could be provided that would only be applicable when a soldier is called to active duty. Many private insurance firms have limitations on their payout in the event of war related incidents. Supplemental insurance would provide payment in the event of a war related death. While American Amicable Insurance Group does extend its life insurance to include war related deaths, most or all other life insurance policies have a war clauses that preclude payment for those engaged in military duty (American-Amicable Insurance Group, 2004).

Company Insurance for those firms that employ Reservists could be offered to assist firms whose employees are called away to active duty. These firms might purchase the insurance to guarantee that they have the financial resources available to find a temporary employee to replace the individual being called up, continue to provide the Reservist health insurance and other benefits in the event of a mobilization, to supplement the pay of the Reservist, and for other damages incurred by the firm in the event that the individual is called away from the firm. The DoD had an ongoing research project involving employer support and the impact that employing Reservists had on employers. This study examines the specific costs employers incur when their Reservist-employees are away from their civilian work on active duty (Department of Defense, 2004). While the results of this study are not available at the time of this writing, they will clearly provide important information about the desirability of company insurance and the specific features that might be offered with the product.

Community insurance might protect a community from problems associated with a call up. In the American Samoa example cited above, the community might purchase insurance that would provide a financial means to bring in substitute workers in the event of a major mobilization.

As noted earlier large numbers of individuals indicate that their income increases as a result of a mobilization. This might be the case for an unemployed individual. This is not a trivial group as the 2002 Survey of Spouses of Activated National Guard and Reserve Component Members indicates that 9.7 percent of Reservists are unemployed in the time frame leading up to activation (Caliber Associates, 2003). In this case a financial hardship occurs in the event that the individual is NOT called to active duty. Non Mobilization insurance, that paid off in the event of a non-activation could be offered to those individuals whose income increases in the event of an activation. In an option pricing framework purchasing non mobilization insurance can be viewed as the Reservist selling an additional call option. The increase in pay leaves open the question of why these individuals would simply enlist fulltime in the military. The unemployment situation might be temporary in nature, whereby enlisting in the military full-time for an extended period might not be the optimal solution.

The above seven types of insurance are not exhaustive. Additional types of insurance might be developed to address other needs of Reservists, the military, families of the military, and firms employing Reserve personnel. With these basic insurance types in place, we turn to additional insurance options that might be offered in conjunction with one or more of these basic plans.

\section{Optional Benefits}

While each of the above plans or some combination thereof could be offered, additional benefits might be offered on the policies to meet the needs of various groups. In this section we discuss several options that might be offered as an element of the above basic insurance contracts. Extension of duty insurance might be offered as an additional benefit. Military Reservists are required to serve for a limited amount of time when called to active duty. On occasion, stop-loss orders are issued whereby the military precludes people from retiring. In effect, a stop loss order is a non-voluntary extension of duty. In these instances, an individual who is otherwise eligible for retirement is precluded from doing so. Stop loss orders are generally issued during major military conflicts. To the extent that a Reservist has made plans for a certain expected deployment, additional financial difficulties might be incurred if the tour extends beyond that time. Extension of duty insurance might increase the levels insurance offered in the event 
the duty does not end in a timely fashion. For example, a monthly call up insurance payment as described above might be doubled in the event of an extension of duty. The Single payoff insurance might have a second benefit in the event of an extension of duty. Similar products might be offered to individuals who are called up to active duty on multiple occasions. This product might also be offered to full-time soldiers.

Some Reservists are given substantial notification that they will be called to active duty. Others receive little advance notification. The 2002 Survey of Spouses of Activated National Guard and Reserve Component Members indicates that these differences can be substantial (Caliber Associates, 2003). Table 3 shows the results of the survey by Reserve Component.

Table 3: Advance Notification Of Mobilization

\begin{tabular}{|l|c|c|c|c|}
\hline Notification Component & 24 Hours or Less & $\mathbf{2 - 6}$ days & $\mathbf{1 - 3}$ Weeks & > Month \\
\hline Army National Guard & $8.8 \%$ & $14.7 \%$ & $34.7 \%$ & $41.9 \%$ \\
\hline Air National Guard & $25.9 \%$ & $24.8 \%$ & $39.6 \%$ & $9.7 \%$ \\
\hline Army Reserves & 10.4 & 28.8 & 45.1 & 15.7 \\
\hline Air Force Reserves & 32.9 & 29.1 & 32.2 & 5.8 \\
\hline Naval Reserves & 11.9 & 41.1 & 36.3 & 10.7 \\
\hline Marine Corps Reserves & 1 & 12.1 & 66.2 & 20.7 \\
\hline
\end{tabular}

Additional payments might be made when the activation notification window is short. Surely the shorter window the more difficulties the Reservist will have preparing financially and personally for the mobilization. To the extent that notification falls below some threshold, say 7 days, an additional payment might be made by the insurance.

Stacked and un-stacked insurance options might be offered to those families with multiple persons in the Reserves, much like stacked and un-stacked auto insurance is offered to individuals with multiple automobiles. In the case of a married couple, both of whom are members of the Reserves, various mobilization options might occur. In the event that only one of the two is called to active duty, the financial hardships would be at one level. In the event that both are called to active duty, the hardship might be substantially higher. By offering stacked and unstacked insurance options, the financial needs of the Reservists might be achieved more effectively and at a reduced cost. These options could be modeled after similar features that are offered in automobile insurance policies.

Seasonality adjustments might be offered to individuals whose earnings follow seasonal patterns. For those individuals working in seasonal industries, the extent of the financial hardship associated with a mobilization is dependent upon the season of the year when they serve. The work of teachers and college professors follow the seasons of the school year. The bulk of the work for a farmer in the northern plains states occurs during the summer months. If the farmer is called to active duty in the summer months they experience substantial financial hardship. On the other hand, if they are called to active duty during the winter months, the financial hardship experienced will be much less. The seasonality feature would link the benefits received to the time of year that the individual serves the military.

A hazardous duty supplemental insurance option could be offered to supplement the pay of those in hazardous situations. While the military currently increases the pay of those individuals in hazardous duty situations, this increase in pay may not be sufficient to offset the corresponding hardships. For example, the spouse of an activated Reservist might wish to reduce their work load in order to focus on keeping current of the activities in the war situation. The desire to do this would likely correspond to the danger that the Reservist is faced with. Supplemental hazardous duty pay may permit the spouse to take a leave of absence from their own work. Again, this supplement might be made available to full-time military soldiers as well.

\section{WHO SHOULD PROVIDE THE INSURANCE?}

Several possibilities exist with regard to who should provide the insurance coverage. One candidate is for a private insurer to provide the insurance. Another candidate would be for the federal government to provide the 
insurance. The original RRMIIP product was provided by the government, which was allowed to sub-contract the product if it so desired. Each of these possibilities has advantages and disadvantages and provide distinctly different motivations to the individuals involved. If the program were operated through the federal government, the military would have the incentive to call up those individuals that had no insurance followed by those with increasing levels of insurance. Doing so would minimize the cost of the mobilization to the military. This would very likely not be optimal or fair mobilization strategy and Reservists would certainly factor this risk in their decision making processes. Moreover, if Reservists believed this to be the case, they would purchase insurance in such a way to increase or decrease the chance of being called up for active duty. One solution to this problem would be to treat the amount of insurance that an individual has purchased as confidential information. Those individuals that make mobilization decisions would not have access to information about the amount of insurance purchased by any soldier or class of soldiers. However, the extent that to which this information can remain confidential in the presence of the budgetary pressures of a war is unknown. Even if individual information were private, the military might structure itself to take advantage of the pay provided by the insurance company. In essence, the existence of such insurance might change the optimal mix of active duty and Reservists.

Alternatively, the insurance could be provided through a private company. Such a private program would resolve the insurance based mobilization issue discussed above. Moreover, private insurance firms are experts in designing and implementing insurance products. However, this method is also problematic. A private firm providing this type of insurance would have a financial stake in whether a war was initiated, the length of the war, the magnitude of the war and how the war is fought. This firm should be expected to lobby the military, Congress and the President on behalf of its best interests. Such lobbying may not be beneficial for the nation. Moreover, a private company with a profit motive might price the insurance higher than a federal government offered program.

In the case of a war with relatively few deaths, such as operation Dessert Storm, a private insurer is well equipped to handle the payout. However, not all wars are likely to be fought in such a way. In the instance of Vietnam or the World Wars, where many thousands of soldiers died and many thousands of others became disabled, the payout on such a policy might bankrupt the insuring agency. The federal government on the other hand would have the full taxing power of the United States people to provide payouts on the policy. Some combination of federally provided insurance and private insurance is also possible. This idea was apparently envisioned in the original version of RRMIIP. This might be done in a manner similar to crop insurance for agricultural concerns, where the insurance is administered by private firms, but the insurance is designed and subsidized by the federal government.

\section{WHEN SHOULD A SOLDIER BE ALLOWED TO PURCHASE THE INSURANCE?}

Some parameters would need to be established in the insurance product with regard to when a soldier would be allowed to purchase insurance and how much of the insurance he should be allowed to purchase in order to avoid a moral hazard problem. This element of implementation was clearly problematic in the original RRMIIP. In the absence of such controls, the soldier would be motivated to delay purchasing insurance until a mobilization is imminent. When a mobilization becomes imminent, the soldier would purchase large amounts of the insurance. This was exactly the case that occurred in Operation Joint Endeavor. Such behavior would undermine the viability of the insurance program. In order to preserve an orderly system, some limitations on when an individual is permitted to purchase the insurance must be in place.

One-time purchase would allow soldiers to purchase a fixed amount of the insurance at the time that they enlist in the military only (or for existing soldiers at the time the product is initiated). In this way, the bulk of the moral hazard problem noted above would be avoided. This was the way RRMIIP was originally designed. While simple to administer, and providing a good basic benefit, augmentations to the program can be developed that would enhance the utility of the program to both the military and the Reservist.

In many instances an individuals financial responsibilities change throughout their military career. For example getting married, having children, starting a business or any number of other life events. To meet developing responsibilities, soldiers might be allowed to increase the amount of insurance periodically throughout his/her career. 
As individuals increase in age, very frequently their earning power in the civilian sector also increases. Increasing levels of protection to insure these higher earnings might be desirable. At issue in such a program would be when the soldier would be allowed to increase his insurance and by how much. To the extent that this is not carefully managed an adverse selection problem could develop. Soldiers might be allowed to increase their insurance amount with each military rank promotion. Such a program would be feasible however the individual is insuring his earnings in the private sector, not his military earnings. His earnings in the private sector may or may not correspond with the increase in rank of the soldier. Another candidate is for the soldier to increase the amount of insurance around various life changing events. Such life changing events might include marrying, having a child, the death of a family member as well as other events. Some moral hazard possibilities are also possible here. An individual might choose to marry shortly before being activated simply to increase the amount of insurance that is available in the event of his/her death or mobilization. Finally, soldiers might be permitted to increase their insurance coverage by certain amounts at periodic intervals. For example, the soldier might be allowed to purchase an additional $\$ 300$ of monthly insurance coverage at each annual renewal, regardless of changes.

Alternatively insurance might be based directly on the individual's earnings power in the private sector. Such a program would provide a level of insurance that most closely mirrored the element to be insured (the private sector earnings). The difficulty associated with such a program is that earnings in the private sector change frequently, and as such frequent policy changes would be necessary to implement the program. Complicating this is the possibility of a private sector reduction in wage, such as when an individual becomes involuntarily unemployed. In this case, the insurance might not pay off because the individual has no private sector earnings.

Suspension of new enrollments and insurance level increases would likely be necessary in times when war is imminent to preserve the integrity of the insurance product. Failure to suspend insurance level increases during these times would certainly lead to a moral hazard problem. Such a scenario would certainly have been the case immediately after the events of September 11, 2005.

\section{PRICING AND OTHER CONSIDERATIONS}

Determining an appropriate price for the insurance would be critical to its success. The analysis of the pricing of such a policy can be completed in a standard insurance framework. As each of the products discussed above provide differing benefits they each must be priced separately. While pricing is critical, it is beyond the scope of the current research, and will be undertaken at a later date. In this paper, we do provide initial thoughts on elements that must be considered in pricing the insurance.

At least three possibilities exist with regard to who should pay for the insurance. At one extreme, the soldier would pay for the entire cost of the insurance. If the insurance is priced on an actuarially fair basis under this scenario, the military would have no expenditures on the program. At the other extreme, the military might pay the entire premium for the individual. Clearly every soldier would be motivated to accept the maximum level of insurance regardless of need in this event. As such, the military paying the entire premium, is the equivalent of simply changing the pay structure of military personnel and would not be desirable. In the middle, the individual might pay part of the premium and the military might subsidize the insurance to some degree. While subsidizing the insurance would involve some cost, ideally the military would reap some benefit from the expenditure in the form of improved morale and easier recruiting.

Soldiers might be charged equal premiums or differing premiums. A system whereby each soldier is charged the same premium would be easy to administer, but creates an adverse selection problem. That is, the likelihood that a soldier will be called up for active duty depends on a number of factors including the area of specialty that the soldier has. To rectify this issue, the price of the insurance might be adjusted to reflect the probability that the soldier will be called up for duty. Those soldiers less likely to be called up will be charged a lower premium than those soldiers that are more likely to be called up. A similar problem is faced based on the length of a mobilization. To the extent that different soldiers tend to be called up for differing amount of time, premiums might be adjusted to reflect the different probable insurance payoffs. Doing so however increases the administrative overhead of the program. A similar issue arises with regard to the type of Reservist. Regular Reservists serve their country one weekend per month and two 
weeks per year unless called to active duty. Special Reservists no longer participate in active military duty, but may be reactivated at the option of the military. Clearly both of these groups of people have a financial risk and should be offered insurance; however, the price of the insurance might be adjusted to reflect the probability of being called to active duty.

Premiums might be entirely variable, or they might be a fixed amount plus a variable element. A fixed element might be charged to all Reservists for the right to purchase the insurance. An additional variable charge might apply to those that actually do purchase the insurance. This might allow the military to capture some of the consumer surplus provided by the product. In order to properly price the insurance, the portfolio effects of incorporating the insurance should be integrated into the portfolio framework developed above. Due to space limitations in this paper, such an analysis is not completed here. Rather, the analysis will be incorporated into subsequent research.

\section{WHEN SHOULD THE INSURANCE PAYOFF?}

It also must be determined when the insurance would pay off. Should the insurance pay off in the event of a voluntary mobilization? Clearly when a soldier is non-voluntarily called up, the insurance should provide payment. However, should the insurance pay off when a soldier is voluntarily activated is an open question. Surely, if the insurance did not pay off in the case of a voluntary activation, many soldiers, who would otherwise volunteer for mobilization, would be less inclined to do so. They would wait to be called up on a non-voluntary basis so that the insurance would pay. On the other hand, if the insurance paid on a voluntary basis, there would be an adverse selection problem. Those individuals that have the largest insurance payoff relative to their compensation in the private sector would be most likely to volunteer.

Recall that policy initiatives limit the frequency that a Reservist can be activated. Specifically, they will not be called up for more than one year of duty every six years. Policies by the DOD that limit the number of times an individual can be called up complicate the offering of the product substantially. A soldier that has recently been called up has a strong motivation to drop the insurance immediately after serving a tour of duty. The soldier knows that only by a policy change would he be called up to serve more than once in a six year period. To address this issue, the insurance might be graduated from low premiums to high premiums as the no-call up time period elapses.

Additional complications occur in defining what constitutes a mobilization. Reservists are generally given some notice that the military is considering them for a mobilization. During the time preceding the mobilization Reservists are frequently required to undergo additional training and preparation. At issue is if the insurance should pay at the time that the notice of possible mobilization is issued, or at the time that the mobilization actually occurs.

\section{COMPLICATIONS}

While the concept of the insurance products suggested above can be easily understood, there are substantial complications that arise in the offering and administration of such insurance. These issues must be addressed in order for the product to be successful for both the military and the Reservists. We continue by examining each of these complications in turn.

Soldiers are entitled to retirement benefits upon completion of their tour of duty. The question arises of whether the insurance proceeds should be considered military compensation for retirement benefits. The answer to this question could substantially change the motivations of individuals to purchase the insurance and voluntarily be called up for active duty. While it might improve morale and willingness to serve, certainly additional retirement benefits come with additional costs. The benefits of incorporating the insurance premiums into retirement benefit calculations must be weighed against the cost.

A regular Reservist is required to serve his country two weeks per year and one weekend per month. At issue is if the insurance should pay for those times when an individual would already be on duty. Specifically, should an individual that has been called to active duty be compensated for the two weeks per year and one weekend per month 
when he/she would already be expecting to serve. While this might seem like a trivial issue, the difference would make about a ten percent difference in the payoff of some insurances.

From time-to-time the Reservist may elect to stop paying for some of his insurance. This may occur in cases of insufficient funds to pay the premium or in situations were the Reservist has had a life changing event such that a certain level of insurance is no longer necessary. After children finish college, the Reservist may not feel obligated to hold the same level of insurance as was previously held. The issue is, once reduced, can the soldier reinstate the insurance policy. Certainly in the event that the solider reduced his insurance and there was a subsequent major conflict that increased the probability of being called to active duty, the soldier would be inclined to reinstate the insurance. Some limitations clearly must be placed on those that cancel their insurance and subsequently wish to reinstate it.

\section{CONCLUDING COMMENTS}

This paper addresses three primary issues. First, it discusses the Ready Reserve Mobilization Income Insurance Program (RRMIIP) and why this program failed. Second it develops a framework for analyzing the portfolio characteristics of the stakeholders in a Reservist program. Individual financial characteristics of Reservists are modeled in an options pricing framework to demonstrate the need for and effects of mobilization insurance. Third, it provides suggestions for an alternative insurance program. While these insurance products are simple to understand in concept, properly structuring and pricing the product is an extremely complex task. The paper discusses a number types of insurance along with potential features of the products that might be desirable, along with complications of implementing the insurance product.

The U.S. Military would benefit from this program to the extent that its Reservists are not burdened by a loss of salary in the event that they are called up to active duty. A soldier with a clear mind, knowing that his family is not suffering and that his bills are paid, can be reasonably expected to be a more efficient and effective soldier on the battlefield. The U.S. Military would further benefit from the program to the extent that it became easier to recruit Reserves. Essentially this program would remove one barrier to getting individuals to enter Reserve programs. Reservists would benefit in several ways from the program. First, it would directly reduce the financial exposure that the Reservist faces in the event that he/she is called up for active duty. While this is an important benefit, additional benefits are present. Currently it is advisable for Reservists to take on jobs that can accommodate them in the event that they are called up to active duty, and to make investments that maximize their portfolio in light of their potential active duty responsibilities. These limitations increase the implicit costs of being in the Reserves. By purchasing mobilization insurance, these individuals would be free to take on any occupation they chose and to make any investment they choose. They would be able to do so without the added risk of financial loss. Communities and employers can also benefit as the financial hardship associated with employing individuals in the Reserves, complying with regulations, and accommodating the Reservist in the event of mobilization can be reduced. To the extent that this occurs, employers and communities can be expected to be more supportive of Reserve programs and their participants.

This research is intended as a starting point, and is not intended to provide detailed rules, regulation, or pricing of these insurance products. Additional research needs to be done to fully develop the insurance product and establish equitable pricing of the product. This research might begin by examining the portfolio characteristics of all interested parties, both without the insurance product and with the insurance product. In addition, interested stakeholders should be surveyed to determine what types of insurance they need and desire. While certainly there are hurdles to overcome, there is hope for mobilization insurance products.

\section{REFERENCES}

1. American Forces Press Service, United States Department of Defense, DoD Reserve Chief Recommends Suspending Mobilization Insurance, May 1997, p. 1-3.

2. American Amicable Insurance Group (2004), Private Insurance Companies Pay Out Benefits to Soldiers Killed in the Line of Duty, As reported at: http://biz.yahoo.com/prnews/040709/sff046_1.html July 202004. 
3. Caliber Associates (2003), The 2002 Survey of Spouses of Activated National Guard and Reserve Component Members, Commissioned by the Office of the Assistant Secretary of Defense for Reserve Affairs (OASD/RA).

4. Department of Defense (2000), Reserve Component Survey, As referenced by Office of the Secretary of Defense Reserve Affairs, Employer Support of the Guard and Reserve, Congressional Response. House Report 108-187, March 31, 2004.

5. Department of Defense, Washington Headquarters Services, Directorate for Information Operations and Reports, Department of Defense Selected Manpower Statistics Fiscal Year 2002.

6. Department of Defense (2003), Office of the Assistant Secretary of Defense for Personnel and Readiness, Population Representation in the Military Services, 316 pages.

7. Department of Defense (2004), Office of the Secretary of Defense Reserve Affairs, Employer Support of the Guard and Reserve Congressional Response, prepared for House Report 108-187, March 31, 9 pages.

8. Department of Defense (2004b), Office of the Under Seretary of Defense for Personnel and Readiness, Reserve Personnel Compensation Program Review, March 15, 35 pages.

9. Dresang, Joel (2003), Doyle Urges Support for Reservists, The Milwaukee Sentinel March 26 , p. 1. Employer Support for the Guard and Reserves (ESRG) Website as available at http://www.esgr.org/members2/programs.asp?c=mapSOS.html on May 17, 2005.

10. Golden, Jerry (2005), Overview: From the Omega Report, http://www.cybertime.net/ ajgood/jg1-02.html

11. Lee, Deborah (1997), Unsnarling a Reserve Insurance Program Snafu, Defense Issues, vol. 12(22) p. 1-5.

12. McCune, Jenny (2005), SBA Loan Program Offers War Relief to Businesses, Bankrate.com, http://www.bankrate.com/brm/news/biz/Capital_borrowing/20021115a.asp, p. 1-3.

13. Ministry of Defense (2002), Performance Report from The Secretary of State for Defense, p. 28 http://www.mod.uk/linked_files/publications/pdr2001_2002/dpr_2001-02.pdf.

14. National Committee for the Employer Support of the Guard and Reserves Website, (2005) http://www.esgr.org/employers2/programs.asp?c=mapSOS.html, on May 17.

15. Phipps, Jennie (2005), Preparing the Financial Home Front for War, Bankrate.com, http://www.bankrate.com/brm/news/advice/20021115b.asp, p. 1-4.

16. Ray, Daniel, and Michael Abramowitz (2005), To be in the Reserves, you Better Have Some, Bankrate.com, http://www.bankrate.com/brm/news/special/19990416.asp, p. 1-3.

17. Reserves 2000, (2005), Militia, www.reserves2000.ca/neglected asset.htm.

18. Stewart, Derek B. (2003), Government Accounting Office Testimony Before the Subcommittee on Total force, Committee on Armed Services, House of Representatives, March 19. 